\title{
Four new species of the Aleiodes compressor Herrich-Schäffer species-group (Hymenoptera: Braconidae: Rogadinae) from South America
}

\section{Cuatro especies nuevas del grupo de especies Aleiodes compressor Herrich-Schäffer (Hymenoptera: Braconidae: Rogadinae) de Sudamérica}

\section{Lidia Sulca ${ }^{1 *}$, Eduardo Mitio Shimbori ${ }^{2}$, Scott Richard Shaw ${ }^{2}$}

\author{
1 Departamento de Entomología, Museo de Historia Natural, Universidad Nacional Mayor de San Marcos. Av. Arenales 1256 Jesús María, Lima 14, Perú. \\ 2 University of Wyoming, Department of Ecosystem Science and Management (3354), 1000 E. University Avenue, Laramie, WY 82071 USA. \\ * Corresponding author: \\ Email Lidia Sulca: lidia.sulca@gmail.com \\ Email Eduardo Mitio Shimbori: shimbori@gmail.com \\ Email Scott Richard Shaw: braconid@uwyo.edu
}

\begin{abstract}
Four new species of the Aleiodes compressor (Herrich-Schäffer) species-group from the Neotropical Region are described and illustrated: Aleiodes segakiato sp. nov. and $A$. lamasi sp. nov. from Peru, A. macro sp. nov. from Argentina, and A. palmito sp. nov. from Mexico. With the addition of these new species, the compressor species-group has ten known species; two from Old World, two from Nearctic Region, and six from Neotropical Region. In addition to the descriptions of the new species, a key to known species is presented, and a new distribution record for $A$. mantiqueirensis Shimbori, Shaw and Penteado-Dias from Ecuador is reported.
\end{abstract}

Keywords: Insecta; taxonomy; biodiversity; parasitoid; Neotropical.

\section{Resumen}

Cuatro especies nuevas del grupo de especies Aleiodes compressor (Herrich-Schäffer) de la Región Neotropical son descritas e ilustradas: Aleiodes segakiato sp. nov. y A. lamasi sp. nov. de Perú, A. macro sp. nov. de Argentina y A. palmito sp. nov. de México. Con la incorporación de las especies nuevas, el grupo de especies compressor tiene diez especies conocidas, dos de ellas son del viejo mundo, dos de la Región Neártica y seis de la Región Neotropical. Además de la descripción de las especies nuevas, se presenta una clave de especies y se reporta el nuevo registro de distribución de A. mantiqueirensis Shimbori, Shaw y Pendeado-Dias en Ecuador.

Palabras claves: Insecta; taxonomía; biodiversidad parasitoide; Neotropical.

\section{Publicación registrada en Zoobank/ZooBank article registered:}

http://zoobank.org/urn:Isid:zoobank.org:pub:72BB8001-F459-4A79-A312-B6705533422D

Acto nomenclatural/nomenclatural act:

Aleiodes lamasi sp. nov. - http://zoobank.org/urn:Isid:zoobank.org:act:DC799A9B-050F-4FB0-AE01-CEE8AB8625C4

Aleiodes macro sp. nov. - http://zoobank.org/urn:Isid:zoobank.org:act:C38621B6-CAE3-4703-BF66-407D97AD7E5A

Aleiodes palmito sp. nov. - http://zoobank.org/urn:Isid:zoobank.org:act:171AF118-F1B6-4192-9E01-9CB1CCD1A1CA

Aleiodes segakiato $s p$. nov. - http://zoobank.org/urn:Isid:zoobank.org:act:441ADBE2-27AF-4461-AB00-0F8A642A29BF

\section{Citación:}

Sulca L., E.M. Shimbori, S.R. Shaw. 2016. Four new species of the Aleiodes compressor Herrich-Schäffer species-group (Hymenoptera: Braconidae: Rogadinae) from South America. Revista peruana de biología 23(3): 227 - 236 (Diciembre 2016). doi: http://dx.doi.org/10.15381/ rpb.v23i3.12857
Información sobre los autores:

LS, EMS and SRS realized the new species description. SRS confirmed the new species. LS and EMS take photographs. LS, EMS and SRS wrote the manuscript.

The authors have declared that no competing interests exist. 


\section{Introduction}

Aleiodes Wesmael 1838 (Hymeoptera, Braconidae) is a derived lineage of Rogadinae, with the highest number of species for any genus within the subfamily (Shaw et al.1997). Since the last publication on neotropical Aleiodes (Shimbori et al. 2016), there are 102 species described for this Region, still being somewhat less than the 143 species known from Nearctic Region (Yu et al. 2012, Shimbori et al. 2015). The subdivision of this highly diverse genus into 18 different species-groups (Shaw et al. 1997, Fortier \& Shaw 1999), and the subsequent series of taxonomic revisions for most of these groups from Nearctic Region (Shaw et al. 1997, 1998a, 1998b, 2006, 2013, Marsh \& Shaw 1998, 1999, 2001, 2003, Fortier 2009), provided a practical framework for taxonomy research on these insects. Despite the necessity of revising the limits and evolutionary relations of some groups (Townsend \& Shaw 2009, Zaldivar-Riverón et al. 2008), this framework is still important, especially for highly diverse and poorly known neotropical fauna, as exemplified by the recent revision of the compressor species-group (Shimbori et al. 2015), and another works on neotropical Aleiodes (Townsend \& Shaw 2009, Shimbori \& Pentado-Dias 2011, Shimbori \& Shaw 2014, Shimbori et al. 2016).

The compressor species-group is a small, monophyletic group (Fortier \& Shaw 1999), with only six species described until now. Some species are known to attack concealed or semi-concealed lepidopteran hosts such as geometrid and notodontid (Shaw 1994; Marsh \& Shaw 2003); however, biology of neotropical species is unknown. Here we present descriptions of four new neotropical species and an extended key to species of the compressor species-group modified from Shimbori et al. (2015).

\section{Methods}

Type specimens of the newly described species are deposited at the Departamento de Entomología, Museo de Historia Natural, Universidad Nacional Mayor de San Marcos, Lima, Peru (MUSM), The University of Wyoming Insect Museum, University of Wyoming, Laramie, Wyoming, USA (UWIM), and the Canadian National Collection, Toronto, Canada (CNC)

For recognition of the subfamily Rogadinae see van Achterberg (1993) and Sharkey (1997). The definition of Aleiodes follows that of van Achterberg (1991) and Shaw (1993). Species-group definitions follow Shaw et al. (1997), Fortier and Shaw (1999), and Townsend and Shaw (2009). Terminology follows Sharkey and Wharton (1997), and Shaw et al. (1997). Microsculpture terminology follows that of Harris (1979). Wing vein terminology follows the system adopted by Sharkey and Wharton (1997). Figures in this paper that are followed by the letter 'S' refer to those in Shimbori et al. (2015).

Images were captured with a 3 MP Leica video camera and a Leica M205C stereomicroscope running Leica Application Suite (LAS) software (Leica Microsystems GmbH, Wetzlar, Hesse, Germany), and focus-stacked using the same software. Some minor adjustments in images and plate preparation were performed in Adobe Photoshop version CS6 (Adobe Systems Inc., San Jose, California, United States of America).
Key to New World species of Aleiodes in the compressor species-group (females)

1. Terga 3-6 entirely orange (Fig. 10S); length of first metasomal tergum about twice as long as apical width (as in fig. 8 of Marsh and Shaw 2003)

Terga 3-6 with brown to dark brown markings or entirely dark brown; length of first metasomal tergum at most $1.4 \mathrm{x}$ its apical width 3

2(1). Occipital carina incomplete, widely weakened at vertex; ocell-ocular distance $0.75-0.85 \mathrm{x}$ shorter than diameter of lateral ocellus; terga $4-7$ granular-coriaceous (Fig. 11S); $6.0-7.0 \mathrm{~mm}$ long

A. palmatus Walley

- Occipital carina complete; ocell-ocular distance about $0.5 \mathrm{x}$ shorter than diameter of lateral ocellus (Fig. 7); terga $4-7$ smooth and shiny larger species, body length about $2 \mathrm{~cm}$ A. macro sp. nov.

3(1). Head honey yellow to orange with black stemmaticum; hind tibia mostly dark brown or yellow, without dark bands 4

- $\quad$ Head dark brown with pale yellow to light brown gena; hind tibia yellow with two dark brown bands (Fig. 5S) or apically brown (Fig. 1) 7

4(3). Stigma bicolored, mostly brown with base and apex yellow (Fig. 7S); antenna mostly honey brown, weakly darkened toward apex $\mathbf{5}$

- $\quad$ Stigma all dark brown; antenna dark brown to black (Fig. 1S) $\mathbf{6}$

5(4). Ovipositor sheaths wide and rounded (Fig. 17); ocell-ocular distance distinctly longer than diameter of lateral ocellus (Fig.13)

\section{A. palmito sp. nov.}

- Ovipositor sheaths narrower (Fig. 7S); ocell-ocular distance slightly shorter than diameter of lateral ocellus (Fig. 8S)

\section{A. palmatoides Marsh and Shaw}

6(4). Propodeum and metasomal T1 pale yellow (Fig. 3S); ocelli small, ocellocular distance $2 \mathrm{x}$ longer than diameter of lateral ocellus (Fig. 2S) A. mantiqueirensis Shimbori, Shaw and Penteado-Dias

Propodeum and metasomal T1 dark brown (Fig. 22); ocelli moderate sized, ocell-ocular distance less than 1.5x diameter of lateral ocellus (Fig. 19)

A. segakiato sp. nov.

7(3). Propodeum and most of metasomal T1 dark brown; T1 about as long as apical width $A$. marinoni Shimbori, Shaw and Penteado-Dias

Propodeum and metasomal T1 orangish yellow; T1 1.8x longer than its apical width (Fig. 4) A. lamasi sp. nov.

\section{Taxonomic treatment}

\section{Aleiodes compressor (Herrich-Schäffer) species- group}

Included species.- Aleiodes compressor (Herrich-Schäffer) (Europe); A. aligarhensis (Quadri) (India, Spain, Chad); $A$. palmatus (Walley) (North America - Canada and United States of America); A. palmatoides Marsh and Shaw (United States of America - Virginia and North Carolina); A. marinonii Shimbori, Shaw and Penteado-Dias (Brazil); A. mantiqueirensis Shimbori, Shaw and Penteado-Dias (Brazil, Ecuador); A. lamasi new species (Peru), A. segakiato new species (Peru), A. macro new species (Argentina); A. palmito new species (Mexico).

Diagnosis.- Species in this group are characterized by the more or less laterally compressed metasomal apex of females, with T4 - 7 always visible, and T1 nearly parallel sided; ovipositor and sheaths are relatively long and thick, with the sheaths rounded or lanceolate; antenna short with most flagellomeres only slightly longer than wide, antenna shorter than body, about as long as or shorter than forewing; forewing vein $1 \mathrm{CUb}$ more than 2 times longer than $1 \mathrm{CUa}$, vein 1cua slightly inclivous, 
and vein $\mathrm{M}+\mathrm{CU}$ more or less sinuate; hindwing with wing vein RS sinuate, marginal cell narrowest at middle, vein m-cu mostly present and interstitial to just antefurcal, vein $\mathrm{M}+\mathrm{CU}$ a little longer than 1M; apex of hind tibia without modified comb of setae. Males of the known species lack most of the diagnostic characters (e.g. short antenna and laterally compressed metasomal apex), therefore can be only assigned to this group in association with conspecific females.

\section{Aleiodes lamasi Sulca, Shimbori and Shaw, sp. nov.}

(Figs. 1-5)

Holotype.- + , top label: PERU: CU, Tono, Cosñipata valley, Izquierda al hito o pacal 2, 802m, 12 57'48.1"S/71 32'06”, xii.2007, Malaise trap 15, C. Castillo (MUSM).
Paratypes.- 9 , top label: PERU: CU, Cosñipata valley, ca. P.V. Tono, 13.xii.2007, 12 57'48”S/71 32'06”, 862m, Malaise trap 15, C. Castillo (MUSM). , top label: PERU: CU, Cosñipata

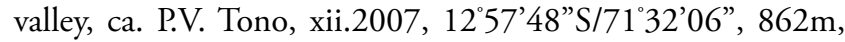
Malaise trap 15, C.Castillo (UWIM). - + , top label: PERU: PU, Sandia, San Pedro de Putina Punco, P.N. Bahuaja Sonene, 1323'29.4”S/6929'00.1”, 322m, 11 - 24.ix.2011. E. Guillermo y E. Rázuri (MUSM).

Diagnosis.- Ocell-ocular distance about as long as diameter of lateral ocellus; occipital carina complete; head color dark brown except mandibles, clypeus, oral space, labial palps, maxillary palps, ventral $1 / 3$ of occiput orangish yellow; metasoma only slightly laterally compressed from apical T3, color of metasomal terga dark brown except basal 2/5 of T1 honey yellow. Propodeum granulate coriaceous basally, rugose coriaceous apically, with median propodeal carina present but incomplete posteriorly.
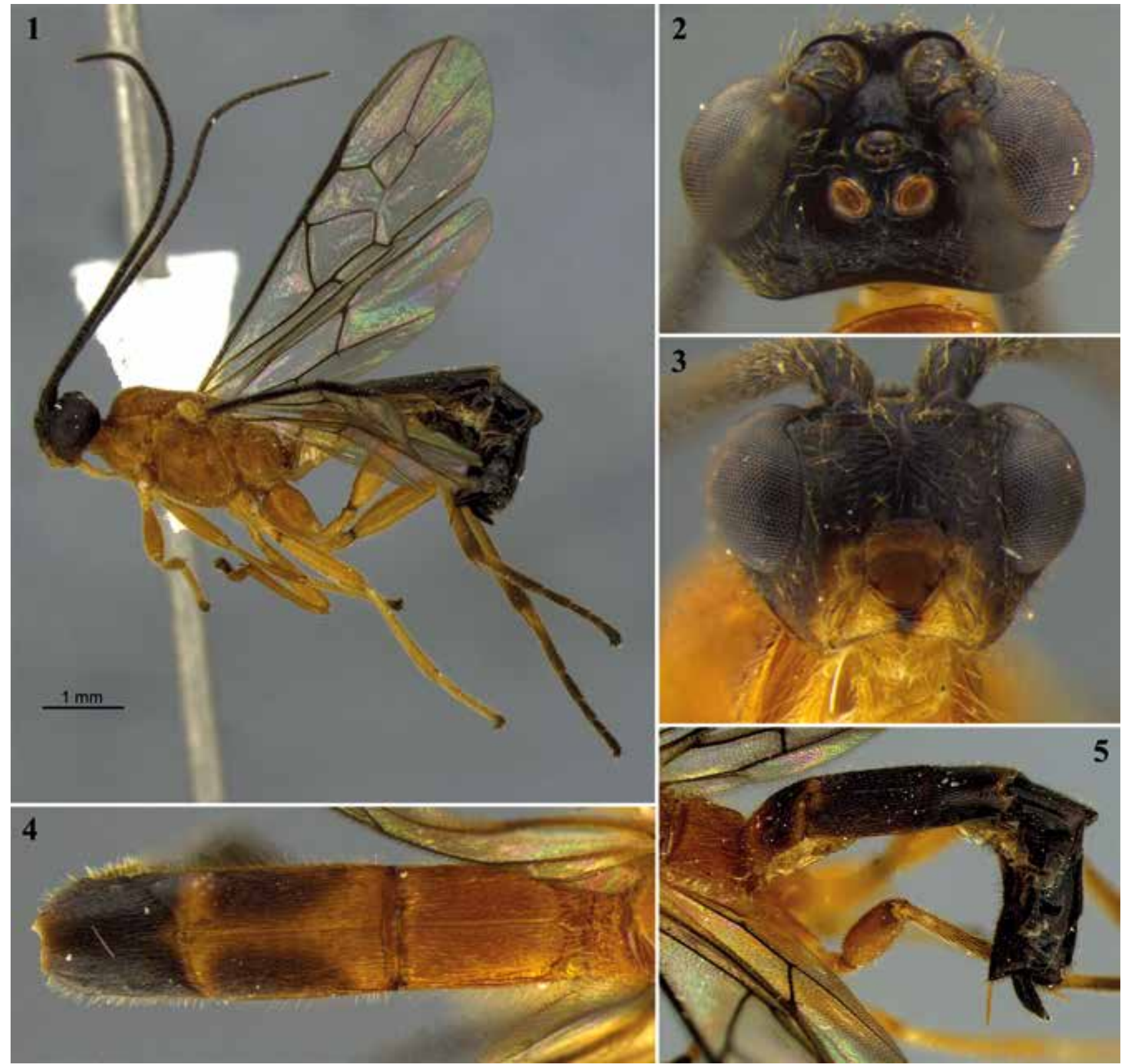

Figures 1 - 5. Details of Aleiodes lamasi sp. nov. (1) habitus, (2) head, dorsal (3) head, frontal, (4) metasomal terga 1 - 3 , dorsal (5) metasoma, lateral. 
Description.- Holotype, female. Body length: $7.5 \mathrm{~mm}$; antenna length: $5.8 \mathrm{~mm}$; forewing length: $5.7 \mathrm{~mm}$.

Color (Fig. 1).- Antenna black. Head dark brown except mandibles, clypeus, oral space, labial palps, maxillary palps, ventral 1/3 of occiput orangish yellow. Mesosoma orangish yellow. Ovipositor sheaths black. Metasoma dark brown dorsally except basal 2/5 of T1, ventrally dark brown except first sternum honey yellow. Wings hyaline with dark brown veins and stigma. Legs: fore and mid legs orangish yellow except $5^{\text {th }}$ tarsomere and claws dark brown; hind leg: orangish yellow slightly darkened except tibia apical $1 / 5$ and tarsi dark brown.

Head (Fig. 2).- Antenna 47 segmented; malar space about as long as basal width of mandible, and approximately $0.5 x$ compound eye height; occipital carina complete and well define at vertex, ventrally touching the hypostomal carina; oral space small and circular, diameter about equal to basal width of mandible; clypeus slightly swollen (Fig. 3); ocell-ocular distance about equal to diameter of lateral ocellus; maxillary palp not swollen; head surface sculpturing finely granulate, but occiput smooth and shining.

Mesosoma.- Sculpturing finely granulate; pronotum with few wrinkles dorso-laterally; notauli weak anteriorly, absent posteriorly; mesoscutum with some longitudinal wrinkles on mid-posterior depressed area; propodeum granulate coriaceous basally, rugose coriaceous apically, and some diverging wrinkles laterally, with mid-longitudinal carina complete.

Wings.- Fore wing: stigma about $5 x$ longer than high; vein $\mathrm{r} 1.1 \mathrm{x}$ vein $2 \mathrm{RS}$ and $1.25 \mathrm{x}$ vein $\mathrm{RS}+\mathrm{Mb}$, and $0.9 \mathrm{x}$ vein $\mathrm{m}-\mathrm{cu}$; vein $3 R$ Sa about $0.5 x$ vein $3 R S b$, and $0.8 x$ vein $2 \mathrm{M}$; vein $1 C U a$ $1.7 \mathrm{x}$ vein $1 \mathrm{cu}-\mathrm{a}$; vein $1 \mathrm{CUb} 2.5 \mathrm{x}$ vein $1 \mathrm{CUa}$; vein $1 \mathrm{M}$ virtually straight, only very slightly curved at basal half. Hind wing: $\mathrm{m}-\mathrm{cu}$ indicated as short pigmented vein interstitial to vein $r-m$; vein $\mathrm{M}+\mathrm{CU}$ about $1.8 \mathrm{x} 1 \mathrm{M}$; vein $\mathrm{r}-\mathrm{m} 2.5 \mathrm{x}$ vein $1 \mathrm{M}$; vein $\mathrm{RS}$ faint, slightly curved at middle.

Legs.- Tarsal claws not pectinate; hind basitarsus $2.4 x$ length of inner apical spur of hind tibia.

Metasoma (Fig. 5).- T1 parallel sided; T1, T2 and basal 1/2 of T3 granulate striate, longitudinal carina present along this sculpturing, remainder visible terga granular (Fig. 4). Ovipositor sheaths about $0.6 x$ length of hind basitarsus, lanceolate apex.

Variation.- Body length $8.33-9.31 \mathrm{~mm}$; otherwise as holotype.

\section{Male.- Unknown.}

Comments.- The color pattern of this new species is quite similar to $A$. marinonii, differing in the color of propodeum and T1, which is mostly dark brown in $A$. marinonii, as compared with orange in $A$. lamasi sp. nov. The antenna is relatively shorter in $A$. marinonii, with 31 antennomeres, as compared with 47 in $A$. lamasi sp. nov. The shape of ovipositor sheaths apex in both species are also different: round in $A$. marionni whereas lanceolate in $A$. lamasi.

Etymology.- This species is named after Dr. Gerardo Lamas, a prominent Peruvian entomologist.

Distribution.- Known only from Peru (Cusco, Puno).
Aleiodes macro Sulca, Shimbori and Shaw, sp. nov.

(Figs. 6-11)

Holotype.- +, top label: ARGENTINA: Entre Ríos, Feb. ' 62 [ii.1962], Pronunciamiento (UWIM).

Diagnosis.- Ocell-ocular distance about 0.5x lateral ocellus; occipital carina complete; head orangish yellow except mandibles tips, ocellar triangle and occipital carina dark brown; metasoma laterally compressed from apical T3, color of metasomal terga orangish yellow dorsally, ventrally honey yellow. Propodeum granulate anteriorly with wrinkles posteriorly, mid-longitudinal carina complete.

Description.- Female: Body length $18.62 \mathrm{~mm}$; antenna length $9.8+\mathrm{mm}$; fore wing length $10.8 \mathrm{~mm}$.

Color (Fig. 6).- Entire body honey brown to bronze except ocellar triangle, mandibles tips and occipital carina dark brown. Antenna black with dorsal scape honey yellow. Wings tinged yellowish veins honey yellow, parastigma honey yellow, stigma dark brown. Legs honey yellow except $5^{\text {th }}$ tarsomere and claws brown. Ovipositor sheaths black. Metasoma orangish yellow dorsally, ventrally honey yellow.

Head (Fig. 7).- Antenna broken, 62 segmented, flagellomeres compact, about as long as wide to slightly shorter; malar space about $0.4 \mathrm{x}$ basal width of mandible, and approximately $0.3 \mathrm{x}$ compound eye height; occipital carina complete and well define at vertex, ventrally touching the hypostomal carina. Oral space small and circular, diameter about $0.7 \mathrm{x}$ basal width of mandible; clypeus slightly swollen; ocell-ocular distance about $0.5 x$ diameter of lateral ocellus (Fig. 9); maxillary palp not swollen; head surface sculpturing finely granulate, but occiput smooth and shining.

Mesosoma (Fig. 11).- Sculpturing coarsely granulate; notauli well defined, deep posteriorly and meeting on depressed area; mesopleuron and metapleuron granulate; propodeum granulate anteriorly with wrinkles posteriorly, mid-longitudinal carina complete.

Wings.- Fore wing: stigma about 3.4x longer than high; vein r $0.88 \mathrm{x}$ vein $2 \mathrm{RS}$ and as long as vein $\mathrm{RS}+\mathrm{Mb}$, and $0.7 \mathrm{x}$ vein $\mathrm{m}-\mathrm{cu}$; vein $3 \mathrm{RSa}$ about $0.5 \mathrm{x}$ vein $3 \mathrm{RSb}$, and $0.94 \mathrm{x}$ vein $2 \mathrm{M}$; vein $1 \mathrm{CUa} 0.5 \mathrm{x}$ vein $1 \mathrm{cu}$-a; vein $1 \mathrm{CUb} 4.5 \mathrm{x}$ vein $1 \mathrm{CUa}$; vein $1 \mathrm{M}$ slightly curved at basal half. Hind wing: $\mathrm{m}$-cu indicated as short pigmented vein just antefurcal to vein $\mathrm{r}-\mathrm{m}$; vein $\mathrm{M}+\mathrm{CU}$ about $1.7 \mathrm{x} 1 \mathrm{M}$; vein $\mathrm{r}-\mathrm{m} 0.85 \mathrm{x}$ vein $1 \mathrm{M}$; vein $\mathrm{RS}$ distinct and strongly sinuate at middle.

Legs.- Tarsal claw not pectinate; hind basitarsus 3.6x length of inner apical spur of hind tibia.

Metasoma (Fig. 10).- T1 parallel sided; T1, T2 and basal 1/3 of T3 granulate striate, longitudinal carina present along T1 and T2. Ovipositor sheaths about 1.1x length of hind basitarsus, lanceolate apex.

Male.- Unknown.

Comments.- Aleiodes macro sp. nov. resembles A. palmatus in having the body color entirely orange, and the petiole long and narrow, about twice as long as apical width and nearly parallel sided. This new species is easily distinguished by the extremely long body, measuring almost $2 \mathrm{~cm}$, but ranging from $0.4-0.7$ $\mathrm{cm}$ in other species in the compressor group. 


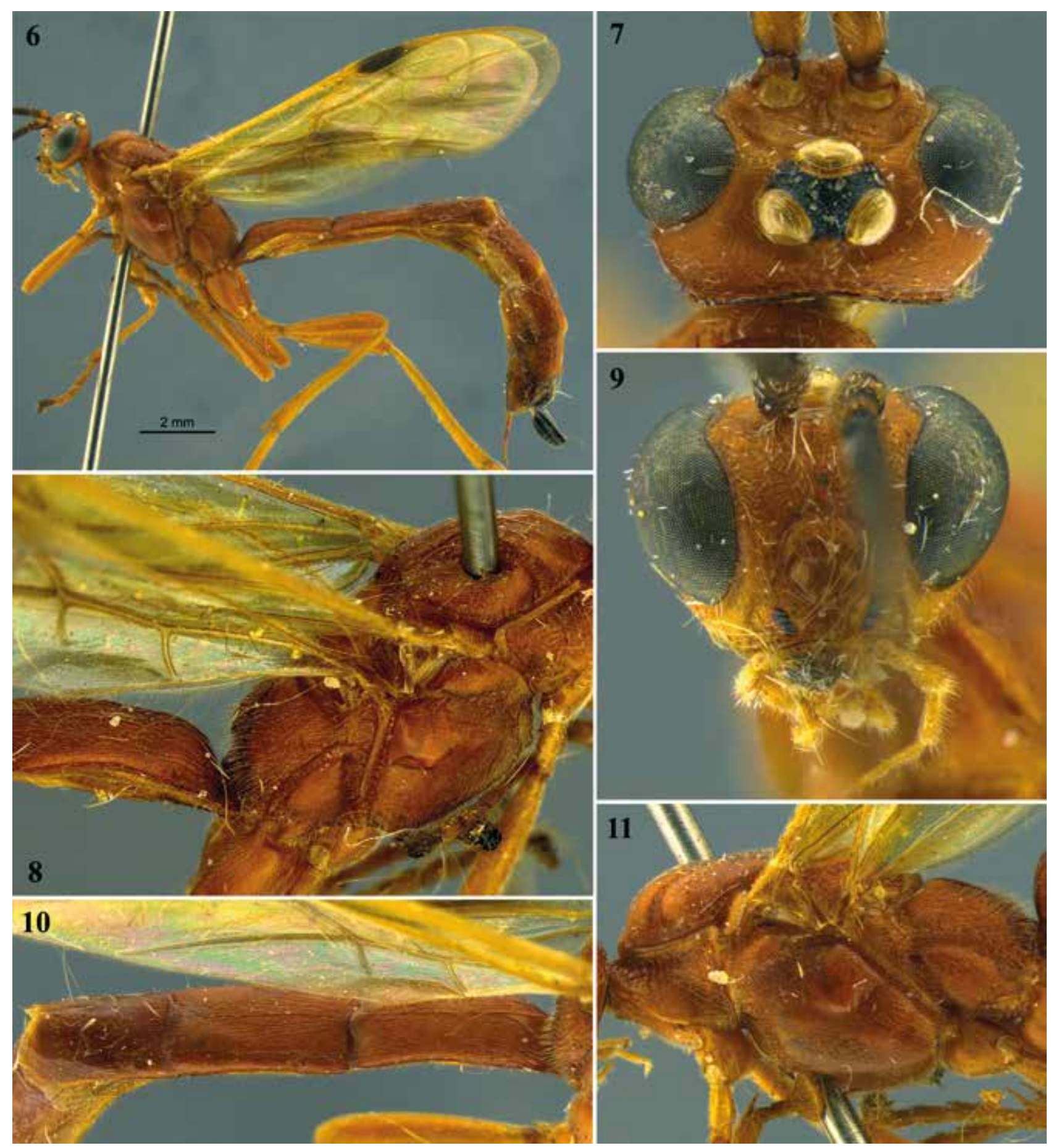

Figures 6 - 11. Details of Aleiodes macro sp. nov. (6) habitus (7) head, dorsal (8) mesosoma, lateral and metasomal terga 1 , lateral (9) head, frontal (10) metasomal terga $1-3$, dorsal (11) mesosoma, lateral.

Etymology.- The specific name is from the Greek macro meaning large, a reference to the unusual large size of this species.

Distribution.- Known only from the type locality in Argentina.

\section{Aleiodes palmito Shimbori and Shaw sp. nov.}

(Figs. 12-17)

Holotype.- + , top label: MEXICO: Sinaloa, 4 1/2 mi. W El Palmito, 6500', 20 July 1964, W.R. Mason (CNC).
Paratypes.- 3 males, MEXICO, Durango, $10 \mathrm{mi}$. W El Salto, 9000', J.E.H. Martin: 2 males 9.VI.1964; 1 male, 4.VII.1964 (CNC).

Diagnosis.- Ocell-ocular distance distinctly longer than diameter of lateral ocellus; occipital carina complete; body mostly honey yellow with faint brown regions on propodeum and $\mathrm{T} 1$; ovipositor sheaths wide and rounded.

Description.- Female: body length $4.9 \mathrm{~mm}$; antenna length $3.0 \mathrm{~mm}$; fore wing length $3.5 \mathrm{~mm}$. 


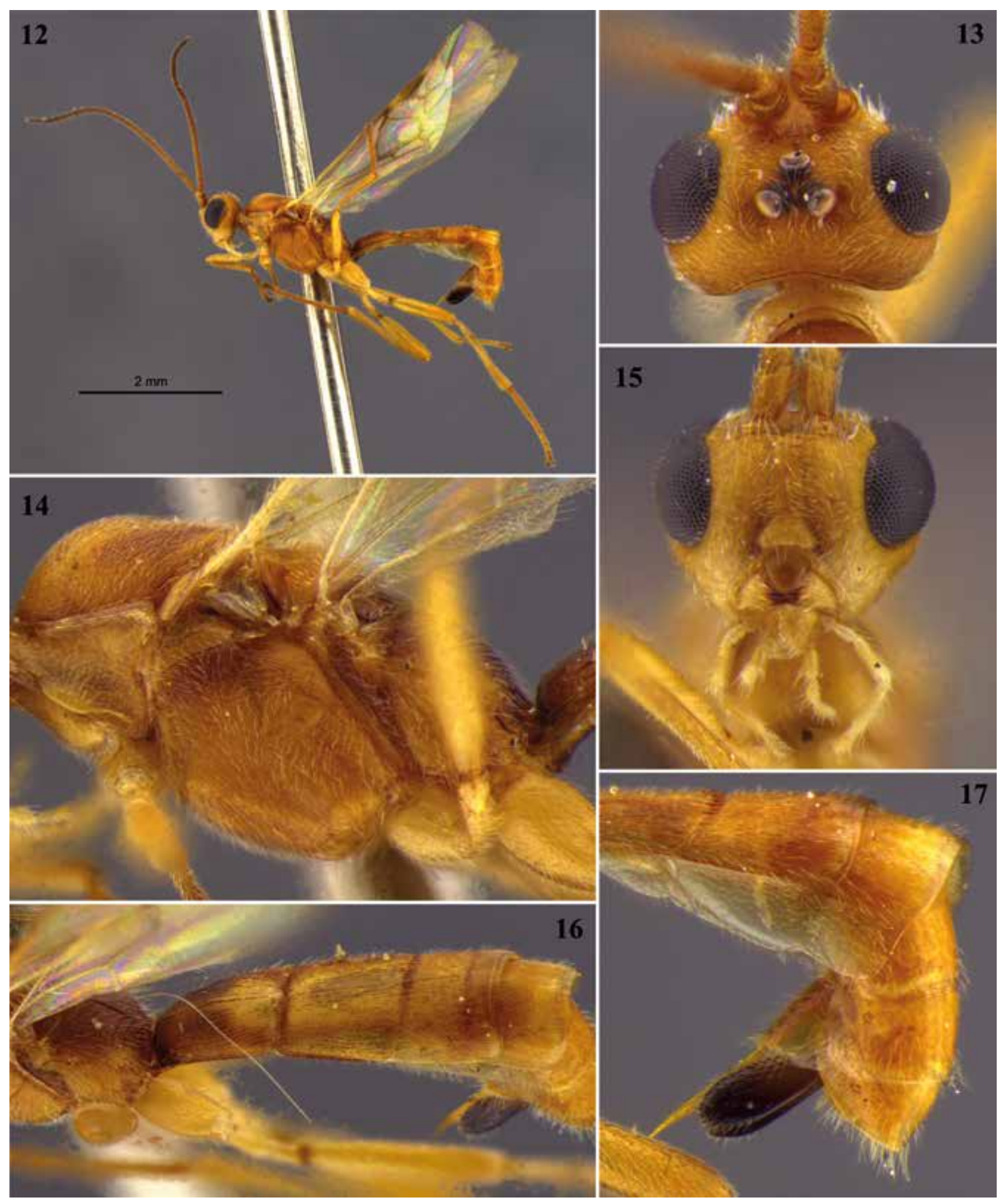

Figures 12 - 17. Details of Aleiodes palmito sp. nov. (12) habitus, (13) head, dorsal (14) mesosoma, lateral (15) head, frontal (16) metasomal tergo $1-4$, dorsal (17) metasomal tergo $2-7$ and ovipositor sheaths, lateral.

Color (Fig. 12).- Honey yellow; propodeum and base o T1 light brown; stemmaticum black; palpi light yellow; antenna mostly honey yellow, darkening toward brown apex. Ovipositor sheaths light reddish brown basally to dark brown apically. Wings hyaline with light brown veins, stigma faint light brown with basal $1 / 4$ and apical tip yellow.
Head (Fig. 13).- Antenna 29 segmented; malar space 1.25x basal width of mandible, and $0.4 \mathrm{x}$ compound eye height; occipital carina complete and well define at vertex, ventrally touching the hypostomal carina. Oral space circular, about as long as basal width of mandible; clypeus slightly swollen (Fig. 15); ocell-ocular distance $1.3 x$ diameter of lateral ocellus; maxillary palpi not swollen; head surface sculpturing finely granulate, occiput smooth and shining. 
Mesosoma (Fig. 14).- Sculpturing finely granulate; pronotum laterally and subalar groove on mesopleuron weakly rugose; notauli weak anteriorly, posteriorly meeting a weakly rugose area; propodeum granulate anteriorly with wrinkles posteriorly, mid-longitudinal carina complete.

Wings.- Fore wing: stigma about $3 x$ longer than high; vein r $0.67 x$ vein $2 R S$, as long as vein $R S+M b$, and $0.6 x$ vein $\mathrm{m}-\mathrm{cu}$; vein $3 R$ Sa about $0.4 x$ vein $3 R S b$, and $0.86 x$ vein $2 \mathrm{M}$; vein $1 C U a$ $2.2 \mathrm{x}$ vein $1 \mathrm{cu}-\mathrm{a}$; vein $1 \mathrm{CUb} 2.4 \mathrm{x}$ vein $1 \mathrm{CUa}$; vein $1 \mathrm{M}$ slightly curved at basal half. Hind wing: $\mathrm{m}$-cu very weakly indicated, just antefurcal to vein $\mathrm{r}-\mathrm{m}$; vein $\mathrm{M}+\mathrm{CU} 1.4 \mathrm{x}$ vein $1 \mathrm{M}$; vein $\mathrm{r}-\mathrm{m}$ $0.8 \mathrm{x}$ vein $1 \mathrm{M}$; vein $\mathrm{RS}$ quite faint, strongly sinuate at middle.

Legs.- Tarsal claw not pectinate; hind basitarsus $4.3 x$ length of inner apical spur of hind tibia.

Metasoma (Fig. 16).- T1 1.2x longer than apical width, apical width $1.3 \mathrm{x}$ basal width; T1T2 and most of T3 basally costate, longitudinal carina present along $\mathrm{T} 1$ and $\mathrm{T} 2$. Ovipositor sheaths $0.8 \mathrm{x}$ length of hind basitarsus, extremely wide and rounded (Fig. 17).

Male.- Body length $3.6-3.8 \mathrm{~mm}$; antenna $3.8-3.9 \mathrm{~mm}$; forewing 3.6-3.8 mm. Antenna with 35 segments. Males differ from female in having antenna, body and forewing with about the same length; metasoma relatively narrower; antenna with more and longer segments (35 vs. 29 in females), flagellomeres about two times longer than wide; and metasomal T4 - 7 darker.

Comments.- The new species is very similar to $A$. palmatoides, differing from it by the diameter of ocelli, being smaller than the ocelli-ocular distance in $A$. palmito sp. nov., as compared with larger than ocelli-ocular distance in A.palmatoides. Aleiodes palmito also has very wide and rounded ovipositor sheaths, being about two times wider than in $A$. palmatoides. Color pattern in both species is quite similar, but the brown markings on the body are fainter in A. palmito. Additionally, A. palmito female has fewer antennomeres (29) than $A$. palmatoides $(33-35)$.

Etymology.- The species was named after the locality El Palmito, in Mexico.

Distribution.- Known only from Durango and Sinaola, Mexico.

\section{Aleiodes segakiato Sulca, Shimbori and Shaw, sp. nov.}

(Figs. $18-23$ )

Holotype.- $\uparrow$, top label: PERU: CUSCO, La Convención, Echarate, C. Segakiato, 11045'38.6”S/73014'57.7”W, 908m, 27.ii.2011, M. Alvarado \& E. Rázuri (MUSM).

Paratype.- 9 , top label: PERU: CUSCO, La Convención, Echarate, C. Segakiato, 11045'38.6”S/73014'57.7”W, 908m, 28.ii.2011, M. Alvarado \& E. Rázuri (UWIM).

Diagnosis.- Ocell-ocular distance about $1.42 \mathrm{x}$ diameter of lateral ocellus; occipital carina complete; head color mostly orange yellow except ocular triangle dark brown; metasoma only slightly laterally compressed from apical T3, color of metasomal terga dark brown with a pale yellow mid-longitudinal spot on T1 - T4. Propodeum rugulose costate with median propodeal carina present and some diverging wrinkles laterally.
Description.- Holotype, female. Body length: $4.7 \mathrm{~mm}$; antenna length: $3.0 \mathrm{~mm}$; fore wing length: $3.5 \mathrm{~mm}$.

Color (Fig.18).- Antenna black. Head orangish yellow, ocular triangle and tips of mandibles dark brown; pronotum orangish yellow. Mesosoma mostly orangish yellow except metanotum and propodeum dark brown. Ovipositor sheaths dark black. Metasoma dark brown with a pale yellow midlongitudinal spot on T1-T4 dorsally, ventrally honey yellow. Wings hyaline with dark brown veins and stigma. Legs mostly honey yellow except dark brown at extreme apex of tibia; fore and mid femur dark brown, hind femur basal 2/11 honey yellow and apical 9/11 dark brown; tarsi light brown.

Head (Fig. 19).- Antenna 30 segmented; malar space about as long as basal width of mandible, and approximately $0.5 x$ compound eye height; occipital carina complete and well define at vertex, ventrally touching the hypostomal carina; oral space small and circular, diameter about equal to basal width of mandible (Fig. 21); clypeus slightly swollen; ocell-ocular distance about $1.4 \mathrm{x}$ diameter of lateral ocellus; maxillary palp not swollen; head surface sculpturing finely granulate, but occiput smooth and shining.

Mesosoma (Fig. 23).- Sculpturing mostly granular coriaceous; notauli weak, shallow and smooth; mesopleuron granular coriaceous; metapleuron with wrinkles posteriorly; propodeum rugose-coriaceous, with mid-longitudinal carina complete and some diverging wrinkles laterally.

Wings.- Fore wing: stigma about $4 \mathrm{x}$ longer than high; vein $\mathrm{r}$ as long as vein $2 \mathrm{RS}$ and vein $\mathrm{RS}+\mathrm{Mb}$, and 0.8 as long as vein $\mathrm{m}$-cu; vein $3 \mathrm{RSa}$ about $0.4 \mathrm{x}$ vein $3 \mathrm{RSb}$, and slightly length than vein $2 \mathrm{M}$; vein $1 \mathrm{CUa}$ as long as vein $1 \mathrm{cu}-\mathrm{a}$; vein $1 \mathrm{CUb} 3.5 \mathrm{x}$ vein $1 \mathrm{CUa}$; vein $1 \mathrm{M}$ moderately curved at basal half. Hind wing: $\mathrm{m}$-cu indicated as short pigmented vein just antefurcal to vein $\mathrm{r}-\mathrm{m}$; vein $\mathrm{M}+\mathrm{CU}$ about $1.3 \mathrm{x} 1 \mathrm{M}$; vein $\mathrm{r}-\mathrm{m} 1.6 \mathrm{x}$ vein $1 \mathrm{M}$; vein RS faint, strongly curved at middle.

Legs.- Tarsal claw not pectinate; hind basitarsus $2.5 \mathrm{x}$ longer than inner apical spur of hind tibia; hind coxa slightly striate dorsally, weak rugosity ventrally.

Metasoma (Fig. 20).- T1 apical $0.7 x$ wider than basal (Fig. 22); T1, T2 and basal 1/2 of T3 granulate striate, longitudinal carina present along this sculpturing, remainder visible terga granular. Ovipositor sheaths thick and apex round, about $0.8 \mathrm{x}$ length of hind basitarsus.

Variation.- Body length (female): $4.6-4.7 \mathrm{~mm}$; antenna length: $2.9-3.3 \mathrm{~mm}$; fore wing length: $3.3-3.5 \mathrm{~mm}$. One paratype with pale yellow spot on $\mathrm{T} 5$.

Male.- Unknown.

Comments.- This new species is very similar to $A$. mantiqueirensis, differing from it in the ocelli-ocular distance, being about 1.4 times longer than the diameter of an ocellus in $A$. segakiato sp. nov, while about 2.0 times in $A$. mantiqueirensis. Both species have the occipital carina complete, but it is well defined at the vertex in $A$. segakiato sp. nov. whereas it is weak in $A$. mantiqueirensis.

Etymology.- Named after the type locality.

Distribution.- Peru (Cusco). 


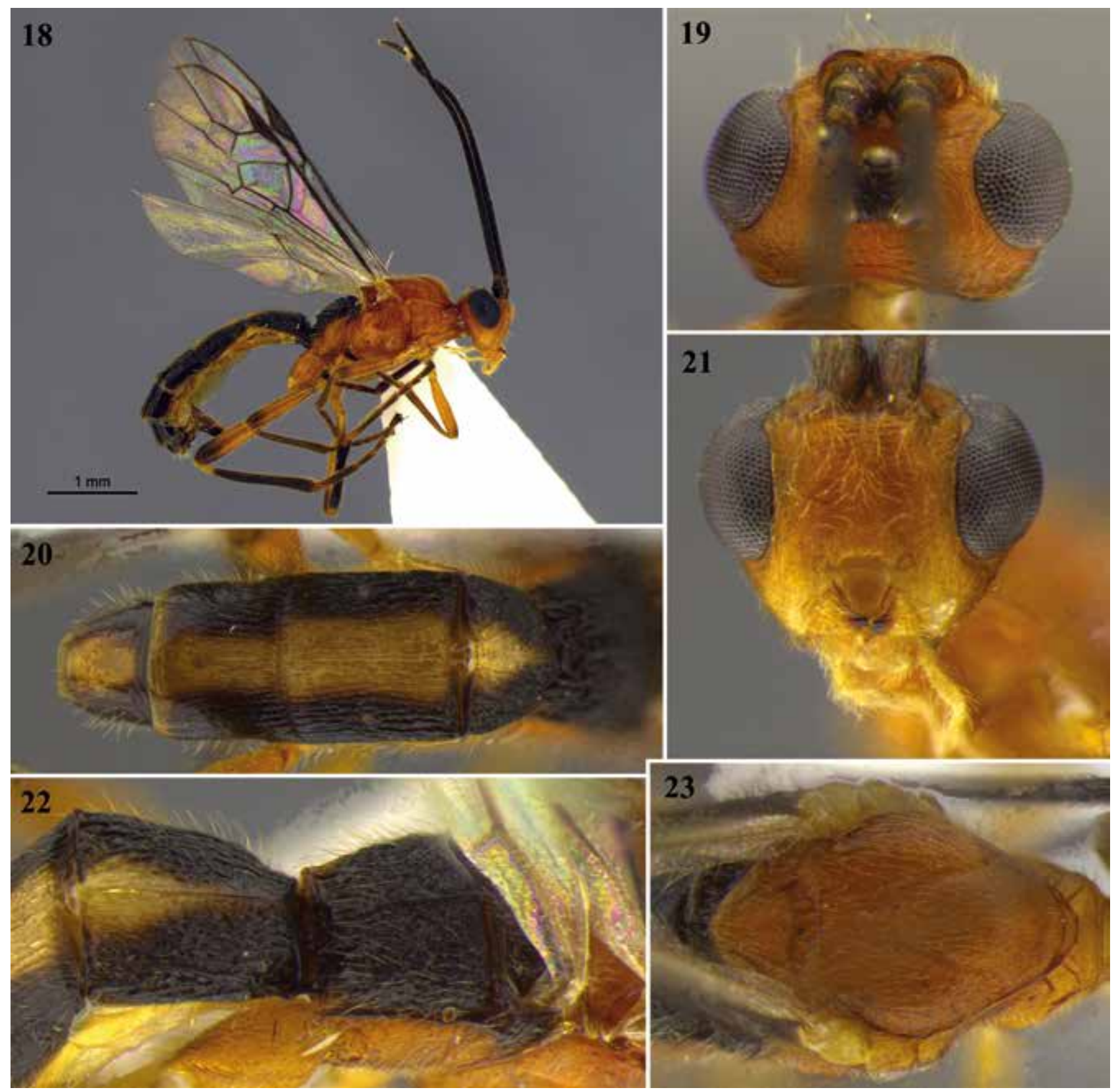

Figures 18 - 23. Details of Aleiodes segakiato sp. nov. (18) habitus, (19) head, dorsal (20) metasomal tergo 1 - 4, (21) head, frontal, (22) propodeum and metasomal terga 1, dorsal, (23) mesonotum, dorsal.

\section{Aleiodes matiqueirensis Shimbori, Shaw and Penteado-Dias}

\section{Aleiodes mantiqueirensis Shimbori et al 2015: 667}

Material examined: Female, ECUADOR: Napo Province, Huahua, Sumaco, KM45 on Hollin-Loretto Road, 15. XII.1989, Malaise Trap, M.J. Wasbauer \& H. Real (CNC)

Comments.- The specimen from Ecuador is virtually identical to the type specimens from Brazil, including the same number of antennal segments, 29. The only difference found when compared with the type series was in the color of propleuron, which is completely orange in the Ecuadorian specimen, as compared with mostly black in the Brazilian specimens.

Distribution.- Recorded from Brazil and Ecuador.

\section{Acknowledgments}

We are thankful Gerardo Lamas and Angelica Maria PenteadoDias, whose support was essential for the realization of this work. L.S acknowledge support from FONDECYT (Peru) through grant 139 -2015 by "Programa de Movilización Internacional IV”. EMS was supported by National Science Foundation grant DEB 14-42110, from the Dimensions of Biodiversity program. Additional financial support for this research was provided by: FAPESP (Fundação de Amparo à Pesquisa do Estado de São Paulo), CAPES (Coordenação de Aperfeiçoamento de Pessoal de Nível Superior), and INCT-HYMPAR SUDESTE (Instituto Nacional de Ciência e Tecnologia dos Hymenoptera Parasitoides da Região Sudeste Brasileira). Any opinions, findings, and conclusions expressed are those of the authors and do not necessarily reflect the views of the National Science Foundation. 


\section{Literature cited}

Fortier J.C. 2009. A revision of the Tetrasphaeropyx Ashmead lineage of the genus Aleiodes Wesmael (Hymenoptera: Braconidae: Rogadinae). Zootaxa, 2256: 1-126.

Fortier J.C. \& S.R. Shaw. 1999. Cladistics of the Aleiodes lineage of the subfamily Rogadinae (Hymenoptera: Braconidae). Journal of Hymenoptera Research, 8: 204-237.

Harris R.A. 1979. A glossary of surface sculpturing. Occasional Papers in Entomology of the California Department of Food and Agriculture, 28: 1-31.

Marsh P.M. \& S.R. Shaw. 1998. Revision of North American Aleiodes (part 3): the seriatus species-group. Proceedings of the Entomological Society of Washington, 100: 395-408.

Marsh P.M. \& S.R. Shaw. 1999. Revision of North American Aleiodes (part 5): the melanopterus species-group. Journal of Hymenoptera Research, 8: 98-108.

Marsh P.M. \& S.R. Shaw. 2001. Revision of North American Aleiodes (part 6): the gasterator and unipunctator species-group. Proceedings of the Entomological Society of Washington, 103: 291-307.

Marsh P.M. \& S.R. Shaw. 2003. Revision of North American Aleiodes (part 7): the compressor, ufei, gressitti and procerus speciesgroups. Proceedings of the Entomological Society of Washington, 105: 698-707.

Sharkey M.J. 1997. Key to New World subfamilies of the Braconidae. In Manual of the New World genera of the family Braconidae (Hymenoptera). Edited by R.A. Wharton, P.M. Marsh, and M.J. Sharkey. International Society of Hymenopterists Special Publication, Washington District of Columbia, United States of America. Pp. 39-63.

Sharkey M.J. \& R.A. Wharton 1997. Morphology and terminology. In Manual of the New World genera of the family Braconidae (Hymenoptera). Edited by R.A. Wharton, P.M. Marsh, and M.J. Sharkey. International Society of Hymenopterists Special Publication, Washington, District of Columbia, United States of America. Pp. 19-37.

Shaw M.R. 1994. Parasitoid host ranges. In: Parasitoid Community Ecology. Edited by B.A. Hawkins and W. Sheehan. Oxford University Press, Oxford, United Kingdom. Pp. 111-144.

Shaw S.R. 1993. Systematic status of Eucystomastax Brues and characterization of the Neotropical species (Hymenoptera: Braconidae: Rogadinae). Journal of Hymenoptera Research, 2: $1-11$.

Shaw S.R., P.M. Marsh, \& J.C. Fortier. 1997. Revision of North American Aleiodes (Part 1): the pulchripes species-group in the New World. Journal of Hymenoptera Research, 6: 10-35.

Shaw S.R., P.M. Marsh, \& J.C. Fortier. 1998a. Revision of North American Aleiodes (Part 2): the apicalis species-group in the New World. Journal of Hymenoptera Research, 7: 62-73.

Shaw S.R., P.M Marsh, \& J.C. Fortier. 1998b. Revision of North American Aleiodes (Part 4): the albitibia and praetor speciesgroups in the New World. Proceedings of the Entomological Society of Washington, 100: 553-565.
Shaw S.R., P.M. Marsh, \& J.C. Fortier. 2006. Revision of North American Aleiodes (Part 8): the coxalis species-group. Zootaxa 1314: 1-30.

Shaw S.R., P.M. Marsh, \& M.A. Talluto. 2013. Revision of North American Aleiodes (Part 9): the pallidator (Thunberg) species-group with description of two new species (Hymenoptera: Braconidae, Rogadinae). Zootaxa, 3608: 204-214. http://dx.doi.org/10.11646/zootaxa.3608.3.4

Shimbori E.M. \& A.M. Penteado-Dias. 2011. Taxonomic contribution to the Aleiodes melanopterus (Erichson) species-group (Hymenoptera, Braconidae, Rogadinae) from Brazil. Zookeys, 142: 15-25. doi: http://dx.doi.org/10.3897/ zookeys.142.1705

Shimbori E.M. \& S.R. Shaw. 2014. Twenty-four new species of Aleiodes Wesmael from the eastern Andes of Ecuador with associated biological information (Hymenoptera, Braconidae, Rogadinae). Zookeys, 405: 1-81. doi: http://dx.doi. org/10.3897/zookeys.405.7402.

Shimbori E.M, A. Penteado-Dias, \& S.R. Shaw. 2015. A revision of the New World species of the Aleiodes compressor species-group (Hymenoptera: Braconidae: Rogadinae). The Canadian Entomologist, 147:665-673. doi: http://dx.doi. org/10.4039/tce.2015.9.

Shimbori E.M, S.R. Shaw, L.F.V. Almeida, \& A.M. Pentado-Dias. 2016. Eleven new species of Athacryvac Braet $\&$ van Achterberg from the Neotropical Region (Hymenoptera, Braconidae, Rogadinae). Zootaxa 4138(1): 83-117. doi: http:// dx.doi.org/10.11646/zootaxa.4138.1.3

Townsend A.C. \& S.R. Shaw. 2009. Nine new species of Aleiodes Wesmael reared at Yanayacu Biological Station (Hymenoptera: Braconidae: Rogadinae) in eastern Ecuador. Journal of Insect Science, 9: 1-37. doi: http://dx.doi. org/10.1673/031.009.3701.

van Achterberg C. 1991. Revision of the genera of the Afrotropical and W. Palearctic Rogadinae Foerster (Hymenoptera: Braconidae). Zoologische Verhandelingen, 273: 1-102.

van Achtergberg C. 1993. Illustrated key to the subfamilies of the Braconidae (Hymenoptera: Ichneumonoidea). Zoologische Verhandelingen, 283: 1-189.

Yu D., van Achterberg C., K. \& Horstmann. 2012. Taxapad 2012 World Ichneumonoidea 2011. Taxonomy, biology, morphology and distribution. On USB Flash drive. www.taxapad. com, Ottawa, Ontario, Canada.

Zaldívar-Riverón A., M.R. Shaw, A.G. Sáez, M. Mori, S.A. Belokoblylskij, S.R. Shaw, et al. 2008. Evolution of the parasitic wasp subfamily Rogadinae (Braconidae): phylogeny and evolution of lepidopteran host ranges and mummy characteristics. BMC Evolutionary Biology, 8: 1-20. doi: http:// dx.doi.org/10.1186/1471- 2148-8-329. 
